This item was submitted to Loughborough's Research Repository by the author.

Items in Figshare are protected by copyright, with all rights reserved, unless otherwise indicated.

\title{
Containing big soda: countering inducements to buy large-size sugary drinks
}

PLEASE CITE THE PUBLISHED VERSION

http://dx.doi.org/10.1016/j.jbusres.2016.07.017

\section{PUBLISHER}

(C) Elsevier

\section{VERSION}

AM (Accepted Manuscript)

\section{PUBLISHER STATEMENT}

This work is made available according to the conditions of the Creative Commons Attribution-NonCommercialNoDerivatives 4.0 International (CC BY-NC-ND 4.0) licence. Full details of this licence are available at: https://creativecommons.org/licenses/by-nc-nd/4.0/

\section{LICENCE}

CC BY-NC-ND 4.0

\section{REPOSITORY RECORD}

Dobson, Paul W., Ratula Chakraborty, and Jonathan S. Seaton. 2019. "Containing Big Soda: Countering Inducements to Buy Large-size Sugary Drinks”. figshare. https://hdl.handle.net/2134/24760. 


\title{
Containing Big Soda: Countering Inducements to Buy Large-Size Sugary Drinks is
}

\author{
Paul W. Dobson ${ }^{\mathrm{a}, *}$, Ratula Chakraborty ${ }^{\mathrm{a}}$, Jonathan S. Seaton ${ }^{\mathrm{b}}$
}

June 2016

${ }^{a}$ Norwich Business School, University of East Anglia, Norwich NR4 7TJ, UK

b Loughborough University, Loughborough LE11 3TU, UK

* Corresponding Author

Email addresses: p.dobson@uea.ac.uk (P. Dobson), r.chakraborty@uea.ac.uk (R. Chakraborty), j.s.seaton@Lboro.ac.uk (J. Seaton)

\section{Acknowledgements}

The authors thank Eitan Gerstner for inspiring this paper through working with him on related research and thank the editors and two anonymous referees for their helpful suggestions to improve the paper. The authors gratefully acknowledge the financial support of the Economic and Social Research Council (Grant RES-000-22-3524). 


\begin{abstract}
Health concerns about overconsumption of large portions apply to a wide range of highly calorific foods and drinks. Yet, amongst all products, sugar-sweetened soft drinks and especially sugared soda are the ones which seem to raise the most ire because they contain little or no nutritional value beyond their sugar content and because of the way that vendors encourage excessive consumption by pricing jumbo-size portions to look like bargains while making smaller portions appear overpriced. This paper considers the logic of such extreme value size pricing and reveals why this marketing practice can harm economic welfare beyond public health concerns. The paper shows why policy interventions, including portion cap rules and soda taxes, seeking to reduce portion sizes and curb the consumption of large-size sugary drinks might fail when they do not fully take into account or appreciate the strategic responses that vendors might adopt to retain value size pricing.
\end{abstract}

Key Words: Portion Sizes; Obesity; Pricing; Sugary Drinks; Soda Tax 


\section{Containing Big Soda: Countering Inducements to Buy Large-Size Sugary Drinks}

\section{Introduction}

Menus with different portion sizes can pose a dilemma for consumers. Consumers like choice but choosing between options often involves weighing up complex trade-offs. Faced with the choice between buying sugared soda at \$1.79 for a 16-ounce cup or $\$ 2.39$ for a 32-ounce cup, which one should the consumer buy? The smaller one might be enough to quench your thirst, but the larger one offers much more for the money. The larger one might boost your energy levels and make you feel more satiated, but the smaller one has only half the calories and can help keep your weight in check. In weighing up these trade-offs you might be leaning towards buying the smaller one, but would you choose differently if instead the respective prices were \$1.79 and \$1.99? You could, of course, consider buying the larger size but have in mind not consuming all of it, but are you sure that you will keep to this intention once you start drinking?

Relative prices can influence the portion size choice and tip the scales one way or the other because all consumers seek value for money from purchases. However, the differences between consumers in their perceptions of the value on offer helps explain why this choice is presented in the first place. The vendor would not offer different sizes if all consumers thought the same way, other than using one size as a decoy to frame the offer price on another size and capture all the sales. Yet, consumers do differ in how they evaluate the value on offer and also at different times according to their changing needs and moods. How best then should the vendor price different sizes to appeal to different sorts or moods of consumers? The evident answer, as clear from its ubiquitous application amongst food and drinks vendors, is by the judicious use of quantity discounts with so-called value size pricing (also known as non-linear pricing or supersized pricing) in structuring prices such that the per unit cost (e.g., price per ounce) 
decreases as portion size increases (NANA, 2002; Harnack \& French, 2003; Haws \& Winterich, 2013). Value size pricing can be a profitable strategy even to the point of selling different sizes with virtually no price difference (Dobson \& Gerstner, 2010).

Bargain offers on large sizes can be irresistible to some consumers and require real determination and discipline for others to turn down alluring offers and stick to a smaller size. Resistance becomes harder the bigger is the discount, but equally the less healthy the product then the greater might consumers try to resist, encouraging the vendor to be even more generous with the size discount. Accordingly, consumers might find the greatest size discounts on the least healthy kinds of foods and drinks. Value-seeking consumers might welcome the offer of large quantities of tasty food and drink at bargain prices. Unfortunately, though, the health consequences for the individual and in aggregate for society could be dire if excessive consumption leads to obesity and ill-health arising from a poor diet. Indeed, the consumption of excessive portion sizes appear to be a significant contributory factor to the alarming rise in obesity levels and resulting healthcare costs to society (Young \& Nestle, 2002; Rolls, 2003; Steenhuis \& Vermeer, 2009; Chandon \& Wansink, 2011) and the availability of enlarged portion sizes encourages overconsumption (Zlatevska, Dubelaar, \& Holden, 2014; Hollands, Shemilt, Marteau, Jebb, Lewis, Wei, Higgins, \& Ogilvie, 2015).

Morgan Spurlock’s 2004 documentary Super Size Me drew considerable public attention to the health dangers associated with supersizing portions sizes and the upsizing selling methods of McDonalds. Despite McDonalds subsequently withdrawing supersize portions, much of the eating out sector continues to use value size pricing and quantity discounting on large portion sizes across a wide range of prepared foods and beverages (NANA, 2002; Nestle \& Young, 2007; Wu \& Sturm, 2013). 
Health concerns apply to overconsumption on a wide range of highly calorific foods and drinks, but sugar-sweetened soft drinks are now the primary target for policymakers seeking to stem the obesity crisis (Nestle, 2015). This paper focuses on these products and considers why vendors use value size pricing, why this pricing practice might harm economic welfare beyond public health concerns about excessive consumption, and whether particular policy measures are likely to be effective in altering the choices presented to consumers to allow for reduced consumption and improved economic welfare.

\section{Policy Issues and Research Challenges}

Sugar-sweetened beverages have a range of healthcare concerns beyond general obesityrelated medical conditions, including diabetes and dental decay. A 20-ounce soda contains around 17 teaspoons of sugar and upwards of 240 calories, while a 64-ounce fountain cola drink could have up to 700 calories (Nestle, 2015). Research shows that people who drink sugary drinks do not feel as full as if they had eaten the same calories from solid food and do not compensate by eating less (Pan \& Hu, 2011). The single-largest source of calories in the American diet in 2010 was sugary drinks, accounting for $46 \%$ of all added sugars consumed, while food and beverage companies spent more than \$800 million for marketing sugary beverages in 2013 and U.S. households bought $\$ 14.3$ billion worth of these products through stores alone (CSPI, 2015). While the average American buys a whopping 170 liters of soda in the course of a year, the U.S. is far from alone in having high per capita consumption and sugary drinks consumption is now a worldwide public health concern (Nestle, 2015). Globally, sugary drinks could be responsible for 184,000 deaths resulting from increased rates of type-2 diabetes, heart disease, and cancer (Singh, Micha, Khatibzadeh, Lim, Ezzati, \& Mozaffarian, 2015). 
Measures to rein in the consumption of sugary drinks are the subject of much policy debate. The two most high profile contemplated measures are a large-size soda ban limiting the size of containers for sugary drinks (such as the unsuccessful attempt to introduce a Sugary Drinks Portion Cap Rule in New York City to limit cup sizes to a maximum of 16 fluid ounces), and a soda tax in the form of either a sales tax or a per unit excise tax applied to sugary drinks (with Britain and South Africa set to follow the lead of Mexico, France and Hungary). Other proposals targeting consumption of large-size sugary drinks range from highly interventionist measures like direct price regulation to oblige vendors to use proportional pricing through to raising consumer awareness about the dangers of overconsumption through hard-hitting advertising campaigns and overt calorie labelling requirements (Chandon \& Wansink, 2012).

A critical issue in devising appropriate policy is to consider the strategic response by vendors to interventions which challenge their profitability. This paper addresses this issue by modelling how a drinks vendor determines its size range and price structure. The modelling shows why policy interventions may have non-linear effects and how accounting for vendor strategic responses can help ensure that measures achieve their intended purpose.

Libertarians may take the view that public health policy interventions which interfere with the free market and individuals' consumption choices amount to unnecessary nanny state interference. Yet, obesity creates a social burden in raising healthcare costs which impact taxpayers and not just the individual (The Economist, 2012). The negative externalities argument alone can give sufficient justification for public health interventions to tackle obesity. However, building on Dobson and Gerstner (2010), this paper provides a further reason on economic welfare grounds to justify policy interventions that specifically target the consumption of large-size sugary drinks. This justification is because vendors may use value size pricing as an instrument to segment consumers in a fashion that is profitable even if the practice destroys 
social value when the difference in willingness to pay for a large-size drink over a more moderate smaller size is less than the difference in supply costs. The analysis here shows that policymakers should not underestimate the determination of vendors to profitably segment consumers and that poorly designed measures which do not fully take this aspect into account can damage rather than improve economic welfare.

The plan for the rest of the paper is as follows. Section 3 sets out a parsimonious model to show why a vendor might use value-size pricing to sell sugary drinks. Section 4 derives the vendor's optimal selling strategy. Section 5 shows why value size pricing can be socially inefficient even if privately profitable. Section 6 why policy interventions might not succeed in reducing consumption and improving economic welfare. Section 7 presents the conclusion.

\section{Model Set-Up}

The purpose of the model is to explore how a vendor might use different sizes of sugary drinks with different relative prices to target different consumer segments and then consider how policy measures might alter the vendor's behavior and affect consumer choices. The focus is on drinks for immediate consumption with purchase and consumption decisions closely aligned and in a simple setting where a profit maximizing vendor decides between offering one or two different sized drinks and how much to charge consumers for them. The vendor could be any type eatery or outlet selling drinks in cups or glasses for immediate consumption.

The vendor offers as a base choice a regular portion size (say, 16 ounces) that allows consumers to drink in moderation at a price $p$ and at a unit cost of supply $c$. In addition or alternatively, the vendor could offer a bigger size and decide on the price, $P$, for this large size (say, 32 or even 50 ounces) with unit cost of supply $C$. If offering both sizes, the vendor determines the price difference for the large size over the regular size, denoting $\Delta p \equiv P-p$, while 
taking account of the unit cost difference, denoting $\Delta c \equiv C-c$. Other costs are fixed and do not affect the vendor's decisions.

The vendor faces two types of consumers: $\theta$ Value-Conscious consumers and $1-\theta$ HealthConscious consumers, where $0<\theta<1$ so normalizing the total number of consumers to equal unity. Denoting $V$ as the Value-Conscious consumers and $H$ as the Health-Conscious consumers, customers of type $i$, where $i=V, H$, are willing to pay $u_{i}$ for the standard regular size and $U_{i}$ for the large size. The difference in these valuations for each consumer type is $\Delta u_{i} \equiv U_{i}-$ $u_{i}$, reflecting how much they gain from trading up from the regular size to the large size.

This bifurcation of consumer segments into value-conscious and health-conscious highlights in plain terms how different consumers, or the same consumers but in different circumstances, make purchasing choices over the amount of appealing-but-unhealthy food and drinks to consume where the value on offer for large sizes tempts some consumers, but health concerns help restrain other consumers to avoid excessive consumption of such goods. Empirical studies provide support for this distinction, showing that price-oriented consumers have a greater propensity to be overweight than less price-conscious consumers (Gandal \& Shabelansky, 2010) and that obesity and unhealthy food and drink consumption rates tend to be higher amongst lower income consumers (Drewnowski \& Specter, 2004). Also, the context might matter with consumers, depending on their mood and circumstances, sometimes having the discipline to control their consumption levels and at other times susceptible to attractive price deals enticing them to consume higher levels (Thaler \& Shefrin, 1981).

The differences between the two consumer segments are formally as follows:

(1) Value-Conscious Consumers: These customers seek value for money in their purchases and are willing to put aside health concerns to consume large quantities of tasty-but-unhealthy food 
and drinks if doing so provides good value and hedonic pleasure from their consumption (Raghunathan, Walker Naylor, \& Hoyer, 2006; Vermeer, Alting, Steenhuis, \& Seidell, 2009). Specifically, they are willing to pay a modest amount, $u_{V}$, for the regular size of the sugary drink but value a large size and are willing to pay significantly more, up to $U_{V}$ with $U_{V} \gg u_{V}$, when they gain a lot of extra consumption pleasure from a significantly enlarged quantity while willing to ignore any longer term effects on their health and waistlines when the large quantity represents good value over the smaller size.

(2) Health-Conscious Consumers: These consumers think about the calories and try to consume in moderation so are willing to pay a premium price, $u_{H}$, for rationing consumption in small portions of sugary drinks and other unhealthy high-calorie products compared to ValueConscious consumers, so $u_{H}>u_{V}$ (Wertenbroch, 1998; Wansink \& Huckabee, 2005). They have major concerns about negative delayed consequences of consuming unhealthy foods and drinks in excessive amounts and so their incremental gain in utility from trading up from the regular size to the large size is less than that of value-conscious consumers, so $\Delta u_{H}<\Delta u_{V}$. Consequently, they are willing to pay little or no more for a larger size of such products compared to the regular size to the extent that the incremental value to them is less than the incremental supply cost, so $0 \leq \Delta u_{H}<\Delta c$, and they will only buy the large size if the price difference with the small size is less than the valuation difference, that is if $\Delta p<\Delta u_{H}$.

For completeness, assuming that $u_{H}>c$ and $U_{V}>C$ ensures that both regular and large sizes are feasible in the market. Also, while the Health-Conscious are willing to pay more for the regular size but that their incremental utility gain from trading up to the large size is less compared to the Value-Conscious, that is respectively $u_{H}>u_{V}$ and $\Delta u_{H}<\Delta u_{V}$, the model allows for either segment to have the higher (absolute) valuation on the large size (recognizing that the 
Value-Conscious have a stronger relative preference for the large size over the regular size but from a lower base so they might not necessarily be willing to pay more than the HealthConscious for the large size, such as when they face a tight budget constraint).

The vendor's objective is to maximize profits through choosing the range and prices of sizes offered, that is whether for regular-only, large-only or regular-and-large size offerings, when knowing the proportions of each customer type and their valuations (i.e., known values of $\theta, u_{V}, u_{H}, U_{V}$ and $U_{H}$ ), but not individuals' preferences (so ruling out direct price discrimination). As the next section shows, the vendor can use value size pricing to entice customers to self-select by their type (i.e., reveal their nature through their purchasing decision) when offering both sizes.

\section{Size Range Choice and Pricing Strategy}

This section derives the vendor's profit-maximizing choice of product sizes to offer and corresponding pricing strategy in the absence of any policy measures influencing the vendor's behavior. The Appendix contains the proofs to all formal propositions and corollaries.

\subsection{Offering Regular Size Only}

The vendor has two pricing options to extract consumer surplus when selling only the regular size. First, the vendor could sell the regular size at a high price of $u_{H}$ only to the HealthConscious consumers (as this price exceeds how much Value-Conscious consumers would be willing to pay, given that $u_{V}<u_{H}$ ). Alternatively, the vendor can sell the regular size at a lower price of $u_{V}$ to attract all consumers. Denoting the former as selling option R1 and the latter as selling option R2 then, as the first two rows of Table 1 show, option R1 generates a profit of (1 $\theta)\left(u_{H}-c\right)$ while option R2 generates a profit of $u_{V}-c$, with the former greater (respectively, less) than the latter when $u_{V}-(1-\theta) u_{H}<$ (respectively, >) $\theta c$. Thus, the vendor is more 
(respectively, less) likely to prefer selling option R1 over option R2 the greater (smaller) is the value of $u_{H}$ and $c$ and the smaller (greater) is the value of $\theta$ and $u_{V}$.

\subsection{Offering Large Size Only}

As a direct alternative to only selling the regular size, the vendor could choose to sell just the large size and use one of four pricing options to extract consumer surplus, depending on whether the vendor wants to supply one or both consumer segments and depending on whether the reservation price for value-conscious consumers buying a large size is greater or less than that for the health-conscious consumers. Labelling these selling options as L1 to L4, Table 1 shows the outcomes and conditions for these four selling options.

Table 1 here.

Taking first the situation where $U_{V} \geq U_{H}$, the vendor has the choice of using selling option L1 and selling to both segments by setting the price at $U_{H}$ or using selling option L2 and selling at $U_{V}$ to exclude the health-conscious and only sell to the value-conscious. The former (respectively, the latter) offers more profit if $U_{H}-\theta U_{V}>(<)(1-\theta) C$. Next, taking the opposite situation where $U_{V}<U_{H}$, then the vendor has the choice of using selling option L3 and selling to both segments by setting the price at $U_{V}$ or using selling option $\mathrm{L} 4$ and selling at $U_{H}$ to exclude the value-conscious and only sell to the health-conscious. The former (respectively, the latter) offers more profit if $U_{V}-(1-\theta) U_{H}>(<) \theta C$.

\subsection{Offering Both Regular Size and Large Size}

Rather than just selling one or the other of the two sizes, the vendor could choose to offer both sizes. This choice would only make sense to the vendor if one consumer segment buys one size while the other consumer segment buys the other size (as otherwise the vendor might as well 
just sell one size in the absence of any kind of framing or other psychological advantage from offering a decoy product that nobody buys). Offering both sizes presents two possibilities, with either the Value-Conscious buying the large size and the Health-Conscious buying the regular size or vice versa, and the challenge for the vendor is to devise a selling strategy which ensures segmentation in the desired way with consumer types self-selecting based on what they see as being the most attractive size choice for the given prices.

The former possibility entails distinguishing between two cases, which Table 1 shows respectively as the vendor using selling options RL1 and RL2. When $U_{V} \geq U_{H}$, RL1 allows the vendor to achieve segmentation in the desired way by pricing the small size at $p=u_{H}$ (which serves to exclude the Value-Conscious buying the small size since then $p>u_{H}$ ) and pricing the large size at $P=U_{V}$ (which serves to exclude the Health-Conscious buying the large size since then $\left.P \geq U_{H}\right)$. When $U_{V}<U_{H}$, the vendor's problem is to price the large size sufficiently low to attract the Value-Conscious, which at most can be $P=U_{V}$, but since this level is less than $U_{H}$ then in order to deter the Health-Conscious buying the large size the price gap with the small size will need to be not more than their value difference, that is $\Delta p \leq \Delta u_{H}$. Accordingly, the vendor can achieve the targeted segmentation using RL2 with the regular size price at $p=U_{V}-\Delta u_{H}$, and so, with $P=U_{V}$, minimizing the necessary price gap, with $\Delta p=\Delta u_{H}$.

The second possibility entails no pricing option available to the vendor that will result in the Value-Conscious buying the regular size and the Health-Conscious buying the large size, observing that only with $p \leq u_{V}$ would the Value-Conscious buy the regular size but at this price nothing prevents the Health-Conscious also buying that size and the vendor is unable to entice them to buy the large size without also enticing the Value-Conscious to do so as well. Specifically, the Health-Conscious require $P<U_{H}$ to buy the large size but that means $P<U_{V}$ 
when $U_{V} \geq U_{H}$ (so the Value-Conscious would then also opt for the large size) or the price would need to be in the range $U_{V}<P<U_{H}$ to deter the Value-Conscious buying the large size when $U_{V}$ $<U_{H}$ but that would entail $\Delta p>\Delta u_{V}$ which by the assumption that $\Delta u_{V}>\Delta u_{H}$ implies $\Delta p>\Delta u_{H}$ so the Health-Conscious would opt for the regular size since this size offers better value to them (i.e., neither type of consumer would buy the large size).

\subsection{Optimal Selling Strategy}

Comparing the amount of profit and consumer surplus that each selling option can extract from the different consumer types determines the vendor's optimal selling strategy shows that the vendor's optimal selling strategy depends on whether or not the willingness to pay of the Value-Conscious for a large size, $U_{V}$, is larger or smaller than that of the Health-Conscious, $U_{H}$ :

PROPOSITION 1. The optimal selling strategy for the vendor is:

(a) When $U_{V} \geq U_{H}$, sell both sizes using $R L 1$ if $(1-\theta)\left(u_{H}-u_{V}\right)>\theta\left(\Delta c-\Delta u_{V}\right)$; otherwise sell only the regular size using $R 2$.

(b) When $U_{V}<U_{H}$, sell both sizes using $R L 2$ if $\theta\left(U_{V}-C\right)>(1-\theta)\left(U_{H}-U_{V}\right)$ and if $(1-$ $\theta)\left(\Delta u_{V}-\Delta u_{H}\right)>\theta\left(\Delta c-\Delta u_{V}\right)$; otherwise, sell only the regular size using $R 1$ if $u_{V}-(1-$ $\theta) u_{H}<\theta$ c or use R2 if instead $u_{V}-(1-\theta) u_{H}>\theta c$.

Two immediate implications follow about the way that the vendor's selling strategy can segment the consumer types into buying different portion sizes by the menu of prices offered:

COROLLARY 1. With optimal dual-size pricing, the vendor offers the large size at a bargain price to attract the Value-Conscious yet put off the Health-Conscious. 
COROLLARY 2. The vendor only uses the large size as a segmentation device to split the consumer types and never uses the large size to attract both consumer types.

These results provide a rationale for why a drinks vendor could employ value size pricing to sell a regular size at a high price with a high margin to Health-Conscious consumers while offering a bargain deal on a large size sold with a substantial quantity discount that entails a low or even negative incremental margin to entice Value-Conscious consumers to buy the large size. The amount of discount the vendor can afford increases as the Health-Conscious customers place less additional value on the large size over the regular size. In the extreme, when they place no additional value on the large size, so $\Delta u_{H}=0$, then the vendor may even offer the large size at no additional charge over the regular size when $U_{V}<U_{H}$. For example, this situation might arise where Health-Conscious customers are completely satiated by consuming the regular size so see no benefit in taking a large size even for the same price. In such circumstances, the vendor could just charge a flat fee and let consumers make their own choice of how much they wish to consume (e.g., as with a self-service soda fountain where the quantity taken is not monitored or with the offer of free refills).

\section{Value Size Pricing and Economic Inefficiency}

Defining total economic welfare purely as the sum of profit and consumer surplus, so leaving aside the negative health effects of excessive consumption, Table 2 shows the welfare levels for each of the four selling options that feature in the vendor's optimal selling strategy from Proposition 1.

Table 2 here.

Comparing the profit and economic welfare levels across the selling options (from respectively columns 2 and 5 of Table 2), reveals that the private interests of the vendor can conflict with societal interests: 
PROPOSITION 2. A vendor can optimize profits by selling both sizes even when the added social value of offering the large size is negative (i.e., when both $\Delta u_{V}-\Delta c<0$ and $\Delta u_{H}-\Delta c<0$ ).

Thus, on top of the public health damage to societal welfare, direct economic harm from value size pricing arises when the resources for providing the additional quantity in the large size cost more than the amount consumers are willing to pay. For the vendor, though, value size pricing still adds to profits when the surplus extraction from the health-conscious consumers on the high regular price is sufficient to cover the additional costs of selling the large size at a bargain price to value-conscious consumers. In this sense, the vendor exploits the discipline of the health-conscious consumers and their reluctance to buy the large size. Society, though, would be better off if the vendor avoided using welfare-destroying value size pricing and instead sold only the regular size to all consumers. The absence of a private incentive to do this results in a social value destruction trap, suggesting a role for public policy intervention to address the harm of such value size pricing to economic welfare, over and above the public health damage caused by overconsumption of such drinks.

\section{Policy Measures to Reduce Overconsumption}

This section considers how the vendor would respond to different policy interventions to see if this changes outcomes in a socially desirable manner by reducing or even eliminating purchases of large-size drinks. The focus is on the two most currently debated policy measures in the form of a portion cap rule and a soda tax.

\subsection{Calibrating Parameters}

The results from Propositions 1 and 2 apply to any specific quantities for the regular and large size. However, calibrating the parameters allows for making straightforward comparisons 
to provide clear and useful insights. First, consider the large size as simply a multiple of the regular size and for convenience take the simplest case where the large size is exactly double the quantity of the regular size, so the regular size is one unit and the large size is two units. Second, assume diminishing returns in the valuations for both consumer types but more so for the valueconscious to fit with the prior assumptions that $u_{V}<u_{H}$ but $\Delta u_{V}>\Delta u_{H}$, and accordingly assume for the 2:1 portion size ratio that $u_{V}<U_{V}<2 u_{V}$ and $u_{H} \leq U_{H}<2 u_{H}$ with $1 / 2<u_{V} / U_{V}<u_{H} / U_{H}$. Third, allow for the possibility of economies of scale in respect of the costs of different drink sizes (e.g. from having similar labor serving costs) such that $c<C \leq 2 c$ for this 2:1 size ratio.

\subsection{Portion Cap Rule (Large-Size Ban)}

Consider the introduction of a portion cap rule which bans the use of the large-size cup so that the maximum cup size that the vendor could use to serve drinks is the regular-size cup. The vendor could respond in one of three ways in ceasing to sell drinks in large-size cups. First, the vendor could sell the regular size at a constant unit price, $p$, but allow consumers to buy two units if they want, so the volume-equivalent price of the large size would be double of the regular size, that is $P=2 p$. Second, the vendor could sell the regular size with the offer of a free refill, so the price on the volume-equivalent of the large size is the same as that of the regular size, that is $P=p$, which makes the vendor's pricing options analogous to selling a large-size only (on the basis that all consumers would accept the free refill when the incremental valuation gain is positive, i.e., $\Delta u_{i}>0$ ), and so a choice between L1, L2, L3 and L4 (from Table 1). Third, the vendor could use multiple-unit pricing to sell the regular size at a given price while offering a bundle deal for buying an additional unit in the form "buy one for $p$ or buy two for $(2-d) p$ ”, where $0 \leq d \leq 1$ is the discount rate on the second unit, and therefore the volume-equivalent price on the large size is $P=(2-d) p$. 
Of the three options, the third one is the most attractive to the vendor because it offers the greatest flexibility, and indeed subsumes the first and second options as special cases with respectively $d=0$ and $d=1$. More importantly for the vendor, the third option with multipleunit pricing allows for precisely-equivalent selling options to RL1 and RL2. This counter measure then allows the vendor to secure almost the same profit level in selling two regular sizes instead of one large size to value-conscious consumers, with the only difference being a slight loss due to raised costs of the amount $\theta(2 c-C)$ arising from the loss of size economies. In this way, the vendor sidesteps and essentially nullifies the ban with little scope for any reduction in consumption of the harmful sugary drinks. Moreover, even with other vendor responses, consumption may not necessarily fall with a large-size ban and indeed could increase. The following proposition summarizes these findings.

Proposition 3. (a) The vendor can effectively sidestep a large-size ban with minimal effect on its profit or on the volume sold by using multiple-unit pricing. (b) Other responses from the vendor might not reduce volume sold and could even allow for an increase as a result of the ban.

The significance of Proposition 3 is that the strategic response by a drinks vendor can negate the intention of a large-size ban and indeed may make the situation worse, notably if the vendor moves to offering free refills. In this context, an additional policy measure to ban free refills might further restrict the vendor's options. Interestingly, France has moved to ban free soda refills and other countries might follow suit (O’Connor, 2015). However, the primary response from the vendor is likely to be multiple-unit pricing. In this regard, Wilson, StolarzFantino, and Fantino (2013) empirically show that such deals could be highly attractive to consumers buying sugary drinks to the extent that buying multiple smaller-sized drinks could even be more desirable than an equivalent volume single large-sized drink. Even so, scope exists 
for a large-size ban to reduce consumption if consumers are reluctant to buy and carry two drinks (which explains the origin of supersizing - Critser 2003), and perhaps the visible absence of large-size drinks might reduce consumption norms towards consuming just a single regular-size drink by playing on consumers’ unit bias (Geier, Rozin, \& Doros, 2006).

\subsection{Soda Taxes}

Instead of seeking to reduce sugary drinks consumptions by restricting consumers’ choice of drinks sizes, an alternative policy measure could be through levying a soda tax on sellers in the hope that this tax would result in higher retail prices and then reduce consumer demand. Soda taxes are generally either in the form of a sales tax (usually as an added percentage on the retail price) or as an excise tax (usually as a monetary amount per weight or volume). Practical differences can arise with collecting the taxes, where normally the vendor pays a sales tax (i.e., as an ad valorem tax), while usually the manufacturer/distributor pays an excise tax, who in turn can then pass on the higher costs down through the supply chain and eventually to consumers.

Going beyond the practicalities of collecting the tax, and acknowledging that the analysis here excludes supply chain considerations, the key difference to consider is how a percentage sales tax and a monetary amount per unit excise tax would respectively affect the vendor. In the case of a sales tax, the vendor's pricing options are still the same as those in Table 1 for $p$ and $P$, but now representing post-tax prices facing consumers. For a sales tax rate of $t$, dividing the revenue elements from column 3 of Table 1 by $(1+t)$ determines the revenues net of tax for the vendor and then subtracting total costs determines net profits. Alternatively, a direct equivalence arises by multiplying the costs by $(1+t)$ to express profits in gross terms (before tax collection). As such, the effect of the sales tax for comparison purposes is to raise the vendor's implicit costs by a fixed multiple of $(1+t)$. In contrast, an excise tax would apply as a fixed amount of $e$ cents 
per unit and in direct proportion to the volume (or sugar content), so the vendor's costs of selling a regular size effectively become $c+e$ while the selling costs of selling a large size at double the size of the regular size are $C+2 e$.

The two taxes are equivalent in taxing the regular size when they have exactly same effect on costs, that is when $c+e=(1+t) c$, which holds when $e=t c$. However, at this level the effect of the excise tax would be greater than the effect of the sales tax on the large size when size economies are present. Observe that with $e=t c$ then the selling costs under the excise tax become $C+2 e=C+2 t c$, where in contrast the selling costs with the sales tax are $(1+t) C$, so the difference is $t(2 c-C)$ which is positive so long as the costs for selling the double-unit large size are less than double the selling costs for selling the single-unit regular size.

This difference might be subtle between the two types of tax but as the vendor's selling costs affect the profits comparisons between the various selling options then they can affect the scope for which the vendor would be willing to offer a bargain deal on the large size and sell it to sell to Value-Conscious consumers. With this consideration in mind, an effective soda tax would need to be set at a level sufficiently high to ensure that the vendor finds it more profitable to sell only the regular size drink, where drawing on the optimality conditions from Table 1, the following findings apply:

Proposition 4. (a) A per unit soda tax can be more effective than a percentage sales tax in deterring the vendor from selling the large size; (b) the sufficient tax level may need to be set high to be effective, increasing in $U_{V}, u_{H}$, and c while decreasing in $U_{H}, u_{V}, \theta$, and $C$.

If the tax rate or tax amount is set too low to alter the vendor's choice of selling option then the vendor simply absorbs the tax and earns lower profits (given that it is already extracting all available surplus with the selling option and so has no scope to increase prices with that 
selling option). This means that rather than the tax having a linear effect on increasing prices, the effect will be fundamentally non-linear in the model here since the vendor will absorb higher taxes until they reach a point where a shift to a different selling option becomes more profitable. Accordingly, half measures will not suffice, and if policymakers want to see change then they will have to set a sufficiently high tax rate or amount to alter the vendor's preference over which selling option to choose. Anything less will not induce the necessary change in behavior.

\section{Conclusion}

Curbing consumption of large sugary drinks is now a key public health objective. However, debate rages over the most appropriate policy measures to use, especially regarding how best to control portion sizes. Policy considerations necessarily require understanding the motives and strategic thinking of drinks vendors and the pricing and marketing tactics they can employ so that policy interventions can anticipate and take into account their responses. As this paper shows, vendors can counter measures in many ways, making effective policy interventions a complex feat.

Considerable opportunities exist for future work on this subject. Fresh insights could emerge from relaxing some of this paper’s modelling assumptions to examine interesting questions about the possibility of using measures to encourage substitution towards less harmful non-sugared drinks and raising consumer conscience to influence purchasing preferences.

However, the greatest challenge remains identifying win-win strategies of mutual benefit to both industry and the public, where the marketing of portion sizes adopts the principle that bigger is not necessarily better, and less can be more. 


\section{Appendix: Proofs of Propositions and Corollaries}

Proof of Proposition 1: (a) When $U_{V} \geq U_{H}$, the five feasible selling options are R1, R2, L1, L2 and RL1. Comparing profits shows RL1 provides strictly more than R1, L1 and L2, and more than R2 if $(1-\theta)\left(u_{H}-u_{V}\right)>\theta\left(\Delta c-\Delta u_{V}\right)$. (b) When $U_{V}<U_{H}$, the five feasible are R1, R2, L3, L4 and RL2. RL2 and R1 respectively provide strictly more profit than L3 and L4, while RL2 offers more profit than R1 if $\theta\left(U_{V}-C\right)>(1-\theta)\left(U_{V}-U_{H}\right)$ and more than R2 if $(1-\theta)\left(\Delta u_{V}-\right.$ $\left.\Delta u_{H}\right)>\theta\left(\Delta u_{V}-\Delta c\right)$, while R1 offers more (less) profit than R2 if $u_{V}-(1-\theta) u_{H}<(>) \theta c$.

Proof of Corollary 1: Follows directly from the optimal pricing choices where, in both dual-size cases with RL1 and RL2, $u_{V}<p \leq u_{H}$ and $\Delta u_{H} \leq \Delta p<\Delta u_{V}$ together with $P=U_{V}$.

Proof of Corollary 2: RL1 profit exceeds L1 and L2 profits, RL2 profit exceeds L3 profit, and R1 exceeds L4 profit, so other selling options dominate all four large-size-only options.

Proof of Proposition 2: The optimality conditions for RL1 and RL2 (against R1 and R2) all allow $\Delta u_{V}-\Delta c<0$ for a range of permissible parameter values. First, when $U_{V} \geq U_{H}$, the optimality condition for RL1 to provide more profit than R1 is $U_{V}>C$ which holds as long as $\Delta u_{H}-\Delta c>-\left(u_{V}-c\right)<0$ and the optimality condition for RL1 over R2 is $(1-\theta)\left(u_{H}-u_{V}\right)>\theta(\Delta c$ $\left.-\Delta u_{H}\right)$ which holds as long as $\left.\Delta u_{V}-\Delta c>-(1-\theta)\left(u_{H}-u_{V}\right) / \theta\right)<0$. Second, when $U_{V}<U_{H}$, the optimality condition for RL2 over R1 is $\theta\left(U_{V}-C\right)>(1-\theta)\left(U_{H}-U_{V}\right)$, which holds if $\Delta u_{V}-\Delta c$ $<0$ as long as $u_{V}-c>(1-\theta)\left(U_{V}-U_{H}\right) / \theta$, and the optimality condition for RL2 over R2 is (1$\theta)\left(\Delta u_{V}-\Delta u_{H}\right)>\theta\left(\Delta c-\Delta u_{V}\right)$, which holds if $\Delta u_{V}-\Delta c>-(1-\theta)\left(\Delta u_{V}-\Delta u_{H}\right) / \theta<0$.

Proof of Proposition 3: (a) The vendor replicates RL1 and RL2 by respectively setting $d=\left(2 u_{H}-\right.$ $\left.\left.U_{V}\right) / u_{V}\right)$ and $d=\left(U_{V}-2 \Delta u_{H}\right) /\left(U_{V}-\Delta u_{H}\right)$, generating the same revenue as in the absence of the 
large-size ban but raising total costs by $\theta(2 c-C)$, which in turn affects the Proposition 1 optimality conditions by the same amount. Segmentation profits decline but only by the extent of lost size economies, and consumption levels remain the same unless the size economies loss tips an already finely balanced profit comparison in favor of R1 or R2. (b) With constant-unit pricing, the vendor could still prefer to sell two units to value-conscious consumers when $U_{V} \geq$ $U_{H}$ using $p=U_{V}-u_{V} \equiv \Delta u_{V}$ to generate a profit of $(1+\theta)\left(\Delta u_{V}-c\right)$, offering more profit than R1 if $(1+\theta) \Delta u_{V}-(1-\theta) u_{H}-2 \theta c>0$ and more than R2 if $(1+\theta) \Delta u_{V}-u_{V}-\theta c>0$, which are both possible if $\Delta u_{V}$ and $\theta$ are high while $u_{H}$ and $c$ are low. Alternatively, offering a free refill is equivalent to using L1, L2, L3 or L4 but which can still yield more profit than both R1 and R2 when $\Delta u_{V}$ and $\Delta u_{H}$ are high and $\Delta c$ is low, despite all consumers taking advantage of the free refill and thus overall consumption levels rising with the ban.

Proof of Proposition 4: (a) Effective taxing requires the vendor finding it more profitable to sell only the regular size drink. When $U_{V} \geq U_{H}$, RL1 yields lower profit than R1 and R2 respectively with a sales tax rate $t>\left(U_{V}-C\right) / C$ and $t>\left[(1-\theta)\left(u_{H}-u_{V}\right)-\theta\left(\Delta c-\Delta u_{V}\right)\right] /[\theta(\Delta c)]$ or an excise tax amount respectively $e>\left(U_{V}-C\right) / 2$ and $e>\left[(1-\theta)\left(u_{H}-u_{V}\right)-\theta\left(\Delta c-\Delta u_{V}\right)\right] / \theta$. When $U_{V}<$ $U_{H}$, RL2 yields lower profit than R1 and R2 respectively with $t>\left[\theta\left(U_{V}-C\right)+(1-\theta)\left(U_{V}-\right.\right.$ $\left.\left.U_{H}\right)\right] /(\theta C)$ and $t>\left[(1-\theta)\left(\Delta u_{V}-\Delta u_{H}\right)+\theta\left(\Delta u_{V}-\Delta c\right)\right] /[\theta(\Delta c)]$, or respectively with $e>\left[\theta\left(U_{V}-C\right)\right.$ $\left.+(1-\theta)\left(U_{V}-U_{H}\right)\right] /(2 \theta)$ and $e>\left[(1-\theta)\left(\Delta u_{V}-\Delta u_{H}\right)+\theta\left(\Delta u_{V}-\Delta c\right)\right] / \theta$. With equivalent tax levels at $e=t c$, all four threshold levels are lower with an excise tax compared to a sales tax when $2 c>C$. (b) Comparative statics show that the thresholds are increasing in $U_{V}, u_{H}$, and $c$ while decreasing in $U_{H}, u_{V}, \theta$, and $C$, so to the extent that the former are higher and the latter are lower then the tax level will need to be set high. 


\section{References}

Chandon, P., \& Wansink, B. (2011). Is food marketing making us fat? A multi-disciplinary review. Foundations and Trends in Marketing, 5, 113-196.

Chandon, P. \& Wansink, (2012). Does food marketing need to make us fat? A review and solutions. Nutrition Reviews, 70, 571-593.

Critser, G. (2003). Fat land: How Americans became the fattest people in the world. Boston: Houghton Mifflin.

CSPI (2015). Facts on sugar drink consumption. Center for Science in the Public Interest. https://cspinet.org/new/pdf/facts-on-sugar-drink-consumption.pdf Accessed 18.04.16.

Dobson, P.W., \& Gerstner, E. (2010). For a few cents more: Why supersize unhealthy food? Marketing Science, 29, 770-778.

Drewnowski, A., \& Specter, S.E. (2004). Poverty and obesity: The role of energy density and energy costs. American Journal of Clinical Nutrition, 79, 6-16.

Gandal, N., \& Shabelansky, A. (2010). Obesity and price sensitivity at the supermarket. Forum for Health Economics \& Policy, 13 (2), Article 9, 1-19.

Geier, A.B., Rozin, P., \& Doros, G. (2006). Unit bias: A new heuristic that helps explain the effect of portion size on food intake. Psychological Science, 17, 521-525.

Harnack, L., \& French, S. (2003). Fattening up on fast food. Journal of the Academy of Nutrition and Dietetics, 103, 1296-1297.

Haws, K.L., \& Winterich, K.P. (2013). When value trumps health in a supersized world. Journal of Marketing, 77 (May), 48-64.

Hollands G.J., Shemilt, I., Marteau, T.M., Jebb, S.A., Lewis, H.B., Wei, Y., Higgins, J.P.T., \& Ogilvie, D. (2015). Portion, package or tableware size for changing selection and 
consumption of food, alcohol and tobacco. Cochrane Database of Systematic Reviews, Issue 9, Article CD011045.

NANA (2002). From wallet to waistline: The hidden costs of super sizing. National Alliance for Nutrition and Activity. http://www.cspinet.org/w2w.pdf Accessed 18.04.16

Nestle, M. (2015). Soda politics: Taking on Big Soda (and winning). New York: Oxford University Press.

O’Connor, R. (2015). France moves to ban free-refill culture of sugary drinks in bid to combat obesity. The Independent, April 2.

Pan, A., \& Hu, F.B. (2011). Effects of carbohydrates on satiety: Differences between liquid and solid food. Current Opinion in Clinical Nutrition and Metabolic Care, 14, 385-390.

Raghunathan, R., Walker Naylor, R., \& Hoyer, W.D. (2006). The unhealthy = tasty intuition and its effects on taste inferences, enjoyment, and choice of food products. Journal of Marketing, $70(4), 170-184$.

Rolls, B.J. (2003). The supersizing of America: Portion size and the obesity epidemic. Nutrition Today, 38 (2), 42-53.

Singh, G.M., Micha, R., Khatibzadeh, S., Lim, S., Ezzati, M., \& Mozaffarian, D. (2015). Estimated global, regional, and national disease burdens related to sugar-sweetened beverage consumption in 2010. Circulation, 132, 639-666.

Steenhuis, I.H.M., \& Vermeer, W.M. (2009). Portion size: Review and framework for interventions. International Journal of Behavioral Nutrition and Physical Activity, 6 (August), 58-67.

Thaler, R.H., \& Shefrin, H.M. (1981). An economic theory of self-control. Journal of Political Economy, 89, 392-406.

The Economist. 2012. The nanny state’s biggest test. December 12. 
Vermeer, W.M., Alting, E., Steenhuis, I.H.M., \& Seidell, J.C. (2009). Value for money or making the healthy choice: The impact of proportional pricing on consumers' portion size choices. European Journal of Public Health, 20, 65-69.

Wansink, B., \& Huckabee, M. (2005). De-marketing obesity. California Management Review, 47 (4), 1-13.

Wertenbroch, K. (1998). Consumption self-control by rationing purchase quantities of virtue and vice. Marketing Science, 17, 317-337.

Wilson, B.M., Stolarz-Fantino, S., \& Fantino, E. (2013). Regulating the way to obesity: Unintended consequences of limiting sugary drink sizes. PLoS ONE, 8 (4), e61081.

Wu, H.W., \& Sturm, R. (2013). What's on the menu? A review of the energy and nutritional content of US chain restaurant menus. Public Health Nutrition, 16, 87-96.

Young, L.R., \& Nestle, M. (2002). The contribution of expanding portion sizes to the US obesity epidemic. American Journal of Public Health, 90, 246-249.

Young, L.R., \& Nestle, M. (2007). Portion sizes and obesity: Responses of fast-food companies. Journal of Public Health Policy, 28, 238-248.

Zlatevska, N., Dubelaar, C., \& Holden, S.S. (2014). Sizing up the effect of portion size on consumption: A meta-analytic review. Journal of Marketing, 78 (May), 140-154. 


\section{Table 1}

Pricing for Regular-Only, Large-only, and Regular-and-Large Size Offerings

\begin{tabular}{|c|c|c|c|}
\hline Selling Option & Amount Sold & Profit & Selection criteria \\
\hline $\mathrm{R} 1: p=u_{H}$ (no large size) & $1-\theta$ regular size & $(1-\theta)\left(u_{H}-c\right)$ & $u_{V}-(1-\theta) u_{H}<\theta c$ \\
\hline R2: $p=u_{V}($ no large size $)$ & 1 regular size & $u_{V}-c$ & $u_{V}-(1-\theta) u_{H}>\theta c$ \\
\hline $\begin{array}{l}\text { L1: } P=U_{H} \text { (no regular size) } \\
\text { when } U_{V} \geq U_{H}\end{array}$ & 1 large size & $U_{H}-C$ & $U_{H}-\theta U_{V}>(1-\theta) C$ \\
\hline $\begin{array}{l}\text { L2: } P=U_{V} \text { (no regular size) } \\
\text { when } U_{V} \geq U_{H}\end{array}$ & $\theta$ large size & $\theta\left(U_{V}-C\right)$ & $U_{H}-\theta U_{V}<(1-\theta) C$ \\
\hline $\begin{array}{l}\text { L3: } P=U_{V} \text { (no regular size) } \\
\text { when } U_{V}<U_{H}\end{array}$ & 1 large size & $U_{V}-C$ & $U_{V}-(1-\theta) U_{H}>\theta C$ \\
\hline $\begin{array}{l}\text { L4: } P=U_{H} \text { (no regular size) } \\
\text { when } U_{V}<U_{H}\end{array}$ & $1-\theta$ large size & $(1-\theta)\left(U_{H}-C\right)$ & $U_{V}-(1-\theta) U_{H}<\theta C$ \\
\hline $\begin{array}{l}\text { RL1: } p=u_{H}, P=U_{V} \\
\left(\Delta p=U_{V}-u_{H}<\Delta u_{V}\right) \\
\text { when } U_{V} \geq U_{H}\end{array}$ & $\begin{array}{l}1-\theta \text { regular size } \\
\theta \text { large size }\end{array}$ & $\begin{array}{l}(1-\theta)\left(u_{H}-c\right) \\
+\theta\left(U_{V}-C\right)\end{array}$ & $(1-\theta)\left(u_{H}-u_{V}\right)>\theta\left(\Delta c-\Delta u_{V}\right)$ \\
\hline $\begin{array}{l}\text { RL2: } p=U_{V}-\Delta u_{H}, P=U_{V} \\
\left(\Delta p=\Delta u_{H}<\Delta u_{V}\right) \\
\text { when } U_{V}<U_{H}\end{array}$ & $\begin{array}{l}1-\theta \text { regular size } \\
\theta \text { large size }\end{array}$ & $\begin{array}{l}(1-\theta)\left(U_{V}-\Delta u_{H}-c\right) \\
+\theta\left(U_{V}-C\right)\end{array}$ & $\begin{array}{l}\theta\left(U_{V}-C\right)>(1-\theta)\left(U_{H}-U_{V}\right) \\
(1-\theta)\left(\Delta u_{V}-\Delta u_{H}\right)>\theta\left(\Delta c-\Delta u_{V}\right)\end{array}$ \\
\hline
\end{tabular}

\section{Table 2}

Welfare with Regular-Only and Regular-and-Large Size Offerings

\begin{tabular}{llccc}
\hline Selling Option & Profit & $\begin{array}{l}\text { Surplus of } \\
\text { Health-Conscious }\end{array}$ & $\begin{array}{l}\text { Surplus of } \\
\text { Value- } \\
\text { Conscious }\end{array}$ & Total Welfare \\
\hline R1: $p=u_{H}$ (no large size) & $(1-\theta)\left(u_{H}-c\right)$ & 0 & 0 & $(1-\theta)\left(u_{H}-c\right)$ \\
R2: $p=u_{V}$ (no large size) & $u_{V}-c$ & $(1-\theta)\left(u_{H}-u_{V}\right)$ & 0 & $(1-\theta) u_{H}+\theta u_{V}-c$ \\
$\begin{array}{l}\text { RL1: } p=u_{H}, P=U_{V} \\
\text { when } U_{V} \geq U_{H}\end{array}$ & $\begin{array}{l}(1-\theta)\left(u_{H}-c\right) \\
\text { RL2: } p=U_{V}-\Delta\left(U_{V}-C\right)\end{array}$ & 0 & 0 & $(1-\theta)\left(u_{H}-c\right)$ \\
when $U_{V}<U_{H}$ & $(1-\theta)\left(U_{V}-\Delta u_{H}-c\right)$ & $(1-\theta)\left(U_{H}-U_{V}\right)$ & 0 & $(1-\theta)\left(u_{H}-c\right)$ \\
\hline
\end{tabular}

